\title{
Outdoor Performance Comparison of Concentrator Photovoltaic and Flat Plate Photovoltaic Systems
}

\author{
Yoshihide Hidaka ${ }^{1, a}$, Kenta Imai ${ }^{1}$,Yasuyuki Ota ${ }^{1}$ and Kensuke Nishioka ${ }^{1}$ \\ ${ }^{1}$ Faculty of Engineering, University of Miyazaki, 1-1 Gakuen-kibanadai-nishi, Miyazaki 889-2192, Japan
}

\begin{abstract}
Output characteristics of tracking type concentrator photovoltaic (CPV) system, multi-crystalline silicon (mc-Si) PV system, CIGS PV system, and amorphous silicon (a-Si) PV system were analyzed in the data period of a year from August 2013 to July 2014.In this study, we analyzed the influence of environmental factors using average photon energy (APE) and temperature of solar cell ( $\left.\mathrm{T}_{\text {cell }}\right)$. The characteristics of $14 \mathrm{~kW} \mathrm{CPV}$ system, $50 \mathrm{~kW} \mathrm{mc-Si}$ PV system, $60 \mathrm{~kW}$ CIGS PV system, $1.35 \mathrm{~kW}$ a-Si PV system were evaluated and compared. As a result, the output performance of $\mathrm{CPV}$ was highest between the four systems at the most frequent conditions in the outdoor environment.
\end{abstract}

\section{Introduction}

Multi-junction solar cells have attracted increasing attention for application in concentrator photovoltaic (CPV) system owing to their very high conversion efficiency [1]. Multi-junction solar cells consisting of InGaP, InGaAs, and $\mathrm{Ge}$ diodes are recognized as super high efficiency cells and are used for space application. Light concentration is one of the most important factors for the development of an advanced PV system using high-efficiency solar cells. High-efficiency multi-junction cells under high light concentration have been investigated for terrestrial application [2,3].

In Japan, there are a few reports in field-test data of CPV systems. Therefore, it is important to accumulate the field-test data of CPV systems and evaluate them. PV systems which are generally used are crystalline-silicon (c-Si) PV system, CIGS PV system and amorphous silicon (a-Si) PV system.

The conversion efficiency of solar cell decreases with increasing temperature [4,5]. Characteristics of CPV are more sensitive to spectrum as compared to flat-plate PV because CPV systems use lens and multi-junction solar cells.

In this study, we analyzed the influence of environmental factors in Japanese meteorological conditions using an index of average photon energy (APE) and temperature [6]. Moreover, we compared CPV, multi-crystalline silicon (mc-Si) PV, CIGS PV, a-Si PV.

\section{Experimental Procedure}

Fig.1 (a) shows a 14 kW CPV system (Daido Steel Co., Ltd.) installed in the University of Miyazaki. Panel area was $7 \mathrm{~m} \times 10 \mathrm{~m}$. A Fresnel lens $(160 \mathrm{~mm} \times 160 \mathrm{~mm})$

\footnotetext{
ahk12040@student.miyazaki-u.ac.jp
}

concentrates sunlight and concentrated light is irradiated onto a triple-junction solar cell $(7 \mathrm{~mm} \times 7 \mathrm{~mm})$. A CPV module was fabricated by connecting 25 lens-cell pairs in series. The $14 \mathrm{~kW}$ CPV system is composed of 96 modules. Fig.1 (b) shows a $50 \mathrm{~kW}$ multi-crystalline $\mathrm{Si}$ (flat plate) PV system. The panel area of this system was $381 \mathrm{~m}^{2}$. Fig.2 (c) shows a $60 \mathrm{kWCIGS}$ (flat-plate) PV system. The panel area of this system was $563 \mathrm{~m}^{2}$. Fig. 2 (d) shows a $1.35 \mathrm{kWa}-\mathrm{Si}$ (flat-plate) PV system. The panel area of this system was $22 \mathrm{~m}^{2}$. These $50 \mathrm{~kW} \mathrm{mc-Si}$ PV system, $60 \mathrm{~kW}$ CIGS PV system and $1.35 \mathrm{~kW}$ a-Si $\mathrm{PV}$ system were also installed in the same site.

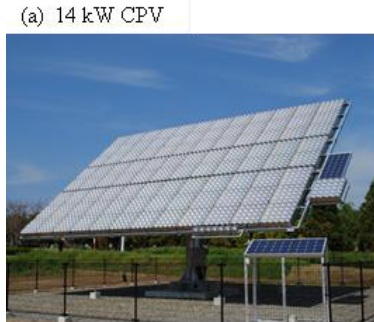

(c) $60 \mathrm{~kW}$ CIGS

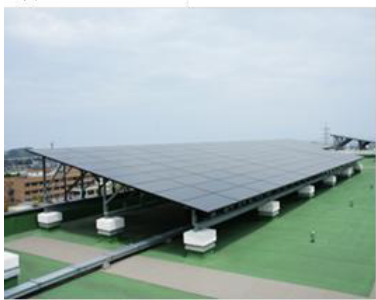

Figure 1. CPV and inUniversityofMiyazaki.

As meteorological data, we measured direct normalized irradiance (DNI), global irradiance (GI), direct solar spectra, and global solar spectra every 1 
minute. DNI and GI were respectively measured by the DNI meter and GI meter. The solar spectrum was measured with the wavelength range from 350 to 1050 $\mathrm{nm}$, the solar spectrum was recoded every 1 minute by a spectro-radiometer (MS700, EKO). Direct solar irradiance was recorded by a spectro-radiometer with a collimation tube (aperture angle: $\pm 2.5^{\circ}$ ).

APE is an index that indicates a spectral irradiance distribution [6]. A value of APE was calculated from measured value of spectral irradiance by dividing the integrated irradiance withthe integrated photon flux density, yielding the average energy per photon $(\mathrm{eV})$ :

$$
\mathrm{APE}=\frac{\int_{\mathrm{a}}^{\mathrm{b}} \mathrm{E}(\lambda) \mathrm{d} \lambda}{\mathrm{q} \int_{\mathrm{a}}^{\mathrm{b}} \Phi(\lambda) \mathrm{d} \lambda}
$$

where $q$ is the electronic charge, Espectral irradiance and $\Phi$ the spectral photon flux density, respectively. For the limitation of our measurement system, aandbwereset to 350 and $1050 \mathrm{~nm}$, respectively. For the CPV system, Fig. 2 shows a flow chart of how the contour graphs were made from APE, $\mathrm{T}_{\text {cell }}$, output energy $\left(\mathrm{P}_{\text {out }}\right)$, and DNI, respectively. The methodology is as follows:

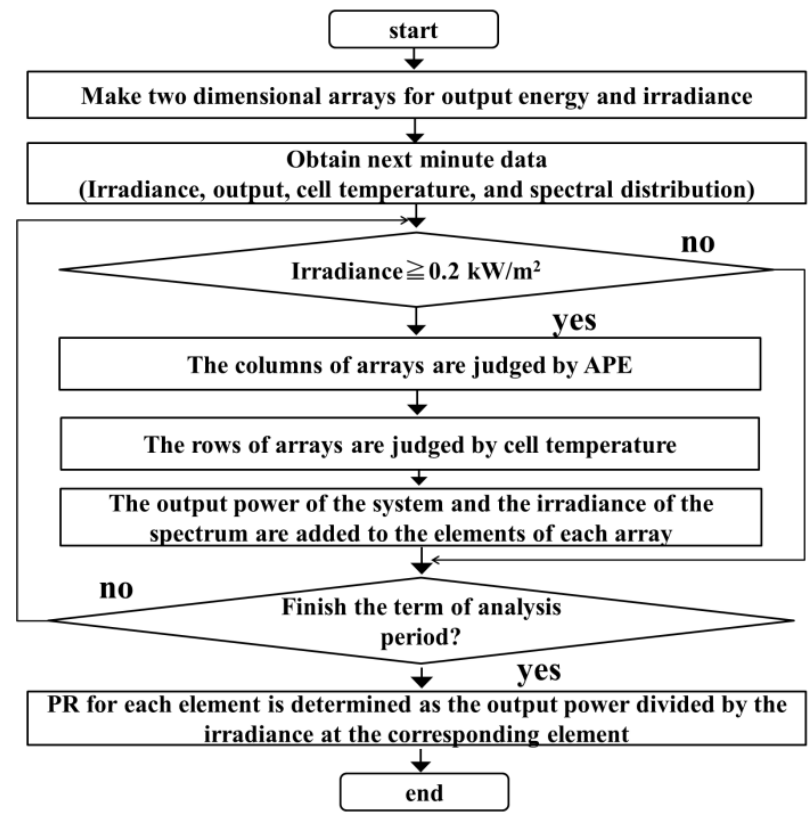

Figure 2. Flow chart of how the contour map was made.

(1) The data of $T_{\text {cell }}$, DNI for $1 \mathrm{~m}^{2}, \mathrm{P}_{\text {out }}$ of the system which has nominal output power of $14 \mathrm{~kW}$, and the spectral irradiance distribution at the analysis period are prepared. The two-dimensional arrays for DNI and for $\mathrm{P}_{\text {out }}$ are prepared. The arrays for $\mathrm{P}_{\text {out }}$ and DNI have APE $(1.80-1.99 \mathrm{eV}, 0.01 \mathrm{eV}$ step $)$ and $\mathrm{T}_{\text {cell }}\left(0-80^{\circ} \mathrm{C}, 5^{\circ} \mathrm{Cstep}\right)$ for column and row, respectively.

(2) The following steps are repeated for the data measured every 1 minute from August 2013 to July 2014. Here, the data with DNI higher than $0.20 \mathrm{~kW} / \mathrm{m}^{2}$ were used and lower performance of system at low DNI was omitted. The reason why we used irradiance higher than $0.20 \mathrm{~kW} / \mathrm{m}^{2}$ was the fluctuation of output voltage, which resulted in fluctuation of the maximum power point tracking (MPPT) control of the inverter. (a) APE of spectrum is determined by the spectrum distribution.

(b) The columns of both $\mathrm{P}_{\text {out }}$ and DNI arrays for the spectrum are indexed by APE.

(c) The rows of both $\mathrm{P}_{\text {out }}$ and DNI arrays for the spectrum are indexed by $\mathrm{T}_{\text {cell }}$. Then, the elements of the arrays for the spectrum are determined.

(d) $\mathrm{P}_{\text {out }}$ of the system and DNI of the spectrum are added to the elements of each array.

(3) Performance ratio (PR) is determined as $P_{\text {out }}$ divided by DNI at the corresponding element. $\mathrm{PR}$ is given as follows:

$$
\mathrm{PR}=\frac{\frac{\mathrm{P}_{\text {out }}(\mathrm{kW})}{\mathrm{DNI}\left(\mathrm{kW} / \mathrm{m}^{2}\right)}}{\frac{\mathrm{P}_{\max }(\mathrm{kW})[\text { rated power of CPV system] }}{1\left(\mathrm{~kW} / \mathrm{m}^{2}\right)[\text { DNI for rating }]}}(2)
$$

where $\mathrm{P}_{\max }$ is the nominal maximum output power under the standard test condition. For the mc-Si, CIGS and a-Si systems, the same method was used for making contour map. GI and solar spectrum without collimation tube were used.

\section{Results and Discussion}

Figure 3 shows the contour maps of PR of CPV, mc-Si PV, CIGS PV, a-Si PV systems as function of APE and $\mathrm{T}_{\text {cell. }}$. In the case of mc-Si, the value of PR decreases with increasing temperature owing to decrease of open-circuit voltage $\left(\mathrm{V}_{\mathrm{oc}}\right)$ [7]. In the case of CPV, the decrease of PR with increasing temperature gets balanced out with the increase of performance owing to the high DNI [8].

In the case of CIGS, the value of PR decreases with increasing $\mathrm{T}_{\text {cell }}$ as mc-Si when APE was more than 1.90 $\mathrm{eV}$. However, PR decreases with decreasing APE when APE was less than $1.88 \mathrm{eV}$. In the case of a-Si, the value of PR increases with increasing temperature owing to anneal effect [9].

Table 1 shows the most frequent conditions for the four systems and the value of PR in four systems at these conditions.

The PR of CPV at most frequent condition had the highest value.

These results indicated that the importance of the understanding of the behavior of the outdoor performance in various PVs and the accurate data of environmental conditions where various PVs are installed. 


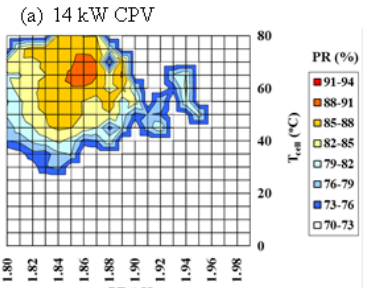

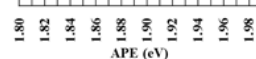

(c) $60 \mathrm{~kW} \mathrm{CIGS}$

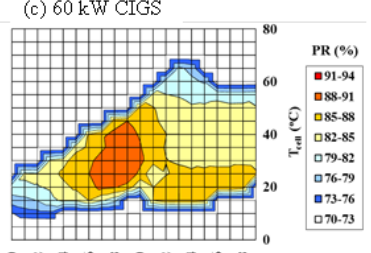

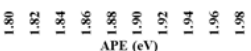

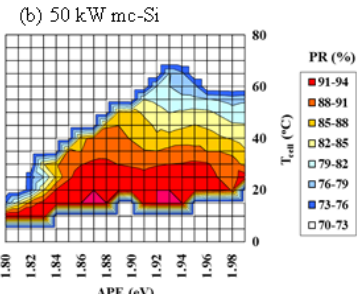

APE (eV)

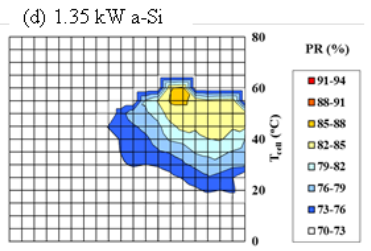

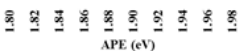

Figure 3.The outdoor performance of $\mathrm{CPV}$ and flat plate systems as function APE and $T_{\text {cell }}$

Table 1

The value of PR at the most frequent conditions in four systems

\begin{tabular}{|c|c|c|c|c|}
\hline & $\mathrm{CPV}$ & $\mathrm{mc}-\mathrm{Si}$ & CIGS & $\mathrm{a}-\mathrm{Si}$ \\
\hline Most & & & & \\
frequent & $1.830 \pm$ & $1.920 \pm$ & $1.920 \pm$ & $1.920 \pm$ \\
condition & 0.005, & 0.005, & 0.005, & 0.005, \\
& $60 \pm 5$ & $45 \pm 5$ & $45 \pm 5$ & $40 \pm 5$ \\
$(\mathrm{APE}(\mathrm{eV})$, & & & & \\
$\left.\mathrm{T}_{\text {cell }}\left({ }^{\circ} \mathrm{C}\right)\right)$ & & & 84.3 & 77.3 \\
\hline $\mathrm{PR}(\%)$ & 86 & 84.5 & & \\
\hline
\end{tabular}

\section{Conclusion}

We analyzed the influence of environmental factors in Japanese meteorological conditions using an index of average photon energy (APE) and temperature. Outdoor performance characteristics of four systems were different. The CPV and mc-Si PV systems were depended to APE and cell temperature, respectably. However, the characteristic of CIGS PV system was intermediate between CPV and mc-Si. The value of PR of $\mathrm{CPV}$ at the most frequent condition was higher than others. The characteristic of a-Si PV system increased owing to anneal effect.

\section{References}

1. M. Yamaguchi, Sol. Energy Mater. Sol. Cells.75, 261 (2003).

2. H. L. Cotal, D. R. Lillington, J. H. Ermer, R. R. King, and N. H. Karam: Proc. 28th IEEE Photovoltaic Specialists Conf (Anchorage, 2000).

3. A. W. Bett, F. Dimroth, G. Lange, M. Meusel, R. Beckert, M. Hein, S. V. Riesen, and U. Schubert,Proc. 28th IEEE Photovoltaic Specialists Conf(Anchorage, 2000).

4. S. M. Sze,Physics of Semiconductor Devices, WileyInterscience Publication(New York, 1981).

5. A.L. Fahrenbruch, R.H. Bube, Fundamentals of Solar Cells, Academic Press Inc(New York, 1983).

6. T. Minemoto, S. Nagae, H. Takakura, Sol. Energy.91, 919(2007).

7. T. Minemoto, Y. Nakada, H. Takahashi, H. Takakura, Sol. Energy.83, 1294(2009).

8. K. Nishioka, T. Takamoto, T. Agui, M. Kaneiwa, Y. Uraoka, Sol. Energy.90, 57 (2006).

9. T. Ishii, K. Otani, T. Takashima, K. Ikeda, Progress in PHOTOVOLTAICS. 22, 949 (2014). 